\title{
A double prevention: how maternal education can affect maternal mental health, child health and child cognitive development
}

\author{
Mariachiara Di Cesare, Imperial College London, UK \\ Ricardo Sabates, University of Sussex, UK \\ r.sabates@sussex.ac.uk \\ Keith M. Lewin, University of Sussex, UK
}

(Received January 2013 Revised August 2013)

doi:10.14301/Ilcs.v4i3.233

\begin{abstract}
This study uses the longitudinal data of Young Lives for Peru to investigate the protective role that maternal education has for children whose mothers suffer from mental health problems. Our first set of findings confirms previous research in this area by showing that maternal education is associated with reduced risk of mental health problems for mothers, and with improved nutrition and cognitive development for their children. We further find that maternal education reduces the burden of maternal mental health problems on child development. This is particularly the case for children of mothers with high levels of education. Unfortunately, for children of mothers with low levels of education, maternal mental health problems continue to predict poor nutritional status and poor cognitive development for children. These results suggest that monitoring and support may be especially important for mothers with lower levels of education if inequalities across generations are to be reduced.
\end{abstract}

Keywords: maternal education, maternal mental health, child nutrition, child cognitive development, Young Lives Study

\section{Introduction}

Mental health represents an important cause of the burden of morbidity and disability in developed and developing countries (Harpham el al., 2003; Murray, Hipwell, Hooper, Stein, \& Cooper, 1996; Stewart, 2007). It is estimated that around 450 million people suffer from mental health problems globally (WHO, 2010a), and that women have a higher susceptibility to mental disorders than men (WHO, 2010b). Poor maternal mental health not only affects women's overall wellbeing but has important inter-generational consequences, which are transmitted directly through the mother-child interactions (Murray, 1992) and indirectly through the family environment and parental relationships
(Grace, Evindar, \& Stewart, 2003; Harpham, Huttly, De Silva, \& Abramsky, 2005; Rahaman, Iqbal, Bunn, Lovel, \& Harrington, 2004). For instance, postpartum depression has been shown to have strong effects on child development, impairing both growth (Harpham et al., 2005; Patel, DeSouza, \& Rodrigues, 2003; Rahaman, Harrington, \& Bunn, 2002; Rahaman et al., 2004; Stewart, 2007), as well as cognitive, emotional, and behavioural outcomes (Black et al., 2007; Lyons-Ruth, Zoll, Connell, \& Grunebaum, 1986; Murray, 1992; Murray \& Cooper, 1997; Patel, Rahman, Jacob, \& Hughes, 2004; Petterson \& Albers, 2001).

Previous research has shown that the overall effect of maternal mental health on child 
development depends on a number of risk and protective factors, of which education plays a key role (WHO, 2010a). Instability in partnership, as a risk factor, not only increases the likelihood of poor maternal mental health and impacts on the emotional development of children, but its overall effect has been observed to be different for mothers with high levels of education, compared with mothers with low levels of education (Wang, Anderson, \& Florence, 2011). Social support, as a protective factor, is provided for mothers to overcome mental health difficulties and to assist with children's needs. Yet, for mothers with high levels of education, social support could be more effective at dealing with the consequences of maternal mental health problems on child development (Feinstein, Duckworth \& Sabates, 2008).

Based on previous studies showing that education is a key protective factor for maternal mental health (Chevalier \& Feinstein, 2006; Robertson, Celasun, \& Stewart, 2003; Ross \& Mirowsky, 1999), this paper proposes to further investigate the direct and indirect effects of mothers' education on maternal mental health and on child development. Two research questions are proposed: (i) Is maternal education directly associated with reduced likelihood of maternal mental health problems and improved developmental outcomes for their children? (ii) Can maternal education indirectly reduce the burden of maternal mental health problems on developmental outcomes for children? To empirically answer these questions, this paper uses the longitudinal data of Young Lives for Peru.

\section{Setting of hypotheses: the role of maternal education}

Education is considered to be one of the main instruments to reduce the transmission of social inequalities within and between generations (CSDH, 2008; Kerr \& West, 2010). In particular, education is crucial for empowering women, giving them knowledge and skills not only to participate in the labour market and in society (Card, 1999), but also to be more efficient at bringing up their children (Feinstein et al., 2008). Research has shown that women with more education place a higher value to their own health and the health of those for whom they care (Duncan \& Brooks-Gunn, 2000); they also have more influence on household decisions and higher levels of civic participation (Malik \& Courtney, 2011). Education can also enable women to provide a cognitively stimulating environment for their children, use language which is developmentally enhancing and support the physical, social, and emotional development of their children (Carneiro, Meghir, \& Parey, 2013).

However, in the delicate equilibrium of intrahousehold relations, the mother-child interactions can be heavily affected by the mental health of the mother (Knitzer, Theberge, \& Johnson, 2008). Mental disorder during pregnancy and the months following childbirth can alter the home environment (Rahaman et al., 2002). It can also reduce mothers' engagement with, and alter mothers' speech towards, the child (Murray, 1992; Murray, Kempton, Woolgar, \& Hooper, 1993) and impact on the overall quality of parenting provision (Murray \& Cooper, 1997). As a result, children of mothers who suffer from mental disorders tend to be affected in their growth (Harpham et al., 2005; Patel et al., 2003; Rahaman et al., 2004), are likely to show emotional and behavioural problems (Field et al., 1988), as well as high rates of insecure attachment and depressive behaviours (Edhborg, Lundh, Seimyr, \& Windstroem, 2001; Lyons-Ruth et al., 1986; Murray, 1992; Murray et al., 1996; Teti, Gelfand, Messinger, \& Isabella, 1995). Poor maternal mental health also has important consequences on children's cognitive functioning and their overall school achievements (Black et al., 2007; Cogill, Caplan, Alexandra, Robson, \& Kumar, 1986; Galler, Harrison, Ramsey, Forde, \& Butler, 2000; Lyons-Ruth et al., 1986; Murray et al., 1993; Patel et al., 2003; Petterson \& Albers, 2001).

Given that maternal education is a key factor for enhancing child development and that maternal mental health problems can hinder this process, the role of maternal education as a protective factor becomes crucial. In order to respond to the two research questions proposed in this paper we formulate the following three hypotheses. First, education can reduce the risk of mental health disorders, in particular depression. This is because education has direct effects on self-esteem, confidence and locus of control which impacts on the overall mental wellbeing (Ross \& Mirowsky, 1999). Previous studies have found that education has a direct association with depression, in particular for women (Chevalier \& Feinstein, 2006), that the impact of education on mental health strengthens with age (Miech \& Shanahan, 2000), and that the 
relationship between education and women's mental health is particularly important during motherhood (Mirowsky \& Ross, 2002; Robertson et al., 2003).

Our second hypothesis is that maternal education can attenuate the negative effects of maternal mental health disorders on child development. Due to their education, mothers who suffer from minor psychiatric disorders can be empowered to better manage their health condition (Duncan \& Brooks-Gunn, 2000; Paxson \& Schady, 2005). Augustine and Crosnoe (2010) show a moderate effect of maternal education on the relationship between maternal depression and children's school achievements. In other words, the magnitude of the relationship between maternal depression and children's school attainment is reduced when maternal education is introduced as a control in the analysis.

Importantly, our third hypothesis is that education can change the nature of the relationship between maternal mental health problems and child development, moderating the consequences of maternal mental health for children and hence affecting the inter-generational transmission of disadvantage (Feinstein et al., 2008). Previous research has shown that, the association between maternal mental disorders in the post-birth period and child development, is stronger among families living in socio-economic deprivation (Stewart, 2007). This suggests that maternal mental illness does not affect children equally within the population. It is possible that maternal education can enhance or hinder existing inequalities (CSDH, 2008).

\section{Methods}

\subsection{Data and sample}

We use data from the first and the second round of Young Lives Longitudinal Study (YL) Peru. The main aim of $\mathrm{YL}$ cohort study is to analyse how poverty affects children's wellbeing (Boyden, 2006). The YL Peru study started in 2002 in 20 sentinel sites, selected on a multi-stage sampling protocol based on poverty status. In each geographical site, households were randomly selected for the study (Wilson, Huttly, \& Fenn, 2006). The selection of households was based on the presence of children belonging to two age cohorts. The youngest cohort was children aged between 6 and 18 months (baseline sample 2,052) and the oldest cohort consisted of children between 7 to 8 years old (baseline sample 714). The second round of YL Peru was conducted in 2006-2007 when the two cohorts were 4 to 5 years old and 11 to 12 years old, respectively.

This paper uses data exclusively from the youngest cohort, as we have information on maternal mental health after birth, as well as on child development, for at least two points during childhood, at age 1 (nutritional status) and at age 5 (cognitive development). The second round of $\mathrm{YL}$ Peru included 1,963 children from round 1; of these only 136 had missing responses for one of the key variables (maternal mental health, child nutritional status at age 1 and child cognitive development at age 5). Since maternal mental health, child nutritional status at age 1 and child cognitive development at age 5 are the outcome variables, and for the rest of the factors used in the analysis, data loss due to missing responses was far less than 1 per cent, we opted not to undertake any imputation. Our final sample consists of 1,821 mothers and their respective children.

The sample strategy for YL has implications for empirical analysis and interpretation of results. First, results from YL cannot be generalised at the country level. The sample as a whole is not nationally representative, but households are representative within geographical sites. Secondly, social and economic gaps between rich and poor households are underestimations of existing inequalities in Peru as a whole. This is because geographical sites were selected based on poverty status, and hence social and economic inequalities reflect the situations of households already living in the selected poor areas. Thirdly, although attrition is a problem in longitudinal studies $(3.5 \%$ for $\mathrm{YL}$ Peru between first and second rounds), Outes-Leon and Dercon (2008) and Sanchez (2009) have found that for $Y L$ the attrition is relatively small, and that there are no systematic differences between households who stopped participating in the study and the rest of the sample.

\subsection{Selection of variables}

Maternal mental health is measured at the interview by the Self-Reporting Questionnaire 20 items (SRQ20). The SRQ20 has been developed by the World Health Organisation (WHO) as an instrument to detect minor psychiatric disorders (WHO, 1994), but without the ability to separate anxiety from depression (Harpham et al., 2005). The 
SRQ20 is based on a series of 20 items/symptoms scoring yes (1) or no (0) with the past 30 days as reference period (hence the maximum score is 20). The variable has been used in previous studies as a dichotomous indicator where more than 7 positive responses to this scale is a proxy measure for the risk of depression. In this paper, we utilise the whole scale of the variable to avoid possible errors of including cases of women at risk of depression when they actually are not. The SRQ20's validity and reliability has been tested in developing countries including some in Latin America such as Nicaragua, Colombia, Ecuador, Brazil and Chile (Harpham et al., 2005; Tuan, Harpham, \& Huong, 2004; WHO, 1994), however it has not been validated for Peru. For the Peruvian case, one may contend that less educated women and women whose native language is Quechua may have problems understanding some of the questions in the SRQ20. Therefore, the SRQ20 may confound ability to understand complex sentences with minor psychiatric disorders (see the estimation method section for the strategy adopted to test for this issue). Additionally we used the Kuder-Richardson Formula 20 (KR-20) to check for the internal SRQ20 consistency. A value of 0.83 suggests that the SQR20 is highly reliable within the study population.

Child development is measured by two outcome variables collected at different stages of childhood to take into account short and long term impacts of maternal mental health. The first variable is child growth, which is measured using height-for-age $Z$ score (HAZ) when children were around 1 year of age. HAZ is commonly used as a proxy measure of early nutritional status (Wisniewski, 2009). The second variable is child cognitive development, measured by the Peabody Picture Vocabulary Test (PPVT) at age 5. The PPVT has been used in other studies showing a strong correlation with the severity of maternal depression (Kiernan \& Huerta, 2008; Murray et al., 1996). In this paper we postulate that maternal mental health has direct impacts on nutrition at age 1 and on cognitive development at age 5, and that cognitive development at age 5 is also affected through the impact of maternal mental health on nutrition.

Maternal education is measured by a dichotomous variable based on years of schooling. We differentiated between mothers with 6 or fewer years of schooling (primary education or less) versus women with more than 6 years of schooling (post-primary education). This cutting point has been selected due to the high enrolment and completion of primary schooling but lower transition into post-primary education in Peru (EPDC, 2009), as well as the potential social benefits of primary school completion (Psacharopoulos \& Patrinos, 2002). We also selected this threshold based on the empirical distribution of years of schooling in the YL data, whereby slightly over half of mothers in the sample have achieved more than 6 years of primary education (see Table 1 ).

Important covariates associated with maternal mental health and child development are: mothers' perceptions on the size of the child at birth, whether the child has had any serious health issues, whether the child resulted from an unwanted pregnancy, whether the child had attended preschool by the age of 5 , whether the mother was in a relationship or not, whether the mother had a disability, household wealth, the number of years living in the current dwelling, number of children, financial difficulties which affected household wealth and regional controls. Table 1 shows descriptive statistics for these variables. 
Table 1. Summary statistics: variable name, description, survey round, mean and standard deviation (s.d.)

\begin{tabular}{|c|c|c|c|c|}
\hline Variable & Variables description & Round & Mean & s.d. \\
\hline Mental Health (mother) & Maternal mental health status (SRQ20 score 0-20) & R1 & 5.60 & 4.15 \\
\hline Nutritional status (child) & Child height-for-age z-score & R1 & -0.75 & 1.29 \\
\hline PPVT score (child) & Child PPVT score (scale from 0 to 95 ) & $\mathrm{R} 2$ & 29.05 & 17.69 \\
\hline Age (child) & Child's age in months & R1 & 11.54 & 3.51 \\
\hline Size at birth (child) & Mother perception of child's birth size: normal to large & R1 & 0.73 & 0.45 \\
\hline Overall Health (child) & Child never had a serious illness & R1 & 0.69 & 0.46 \\
\hline Pregnancy (mother) & Mother had an unwanted pregnancy & R1 & 0.45 & 0.50 \\
\hline Pre-school (child) & Child had attended pre-school by age 5 & $\mathrm{R} 2$ & 0.82 & 0.39 \\
\hline Marital status (mother) & Mother is not in union with partner & R1 & 0.13 & 0.34 \\
\hline Education (mother) & Mothers with more than 6 years of education & R1 & 0.56 & 0.50 \\
\hline Disability (mother) & Mothers with the presence of a disability & R1 & 0.06 & 0.23 \\
\hline Residential stability (household) & Number of years living in the current place of residence & $\mathrm{R} 1$ & 15.93 & 11.07 \\
\hline Wealth index (household) & $\begin{array}{l}\text { Household wealth index (based on three components: housing quality, consumer } \\
\text { durable, services. Value range between } 0 \text { and } 1 \text { ). }\end{array}$ & R1 & 0.47 & 0.23 \\
\hline Children (household) & Number of children in the household & R1 & 2.64 & 2.05 \\
\hline Bad event (household) & Shock that decreased household wealth since the mother was pregnant with child & R1 & 0.39 & 0.49 \\
\hline Place of residence (household) & Household lives in a rural area & R1 & 0.33 & 0.47 \\
\hline
\end{tabular}




\subsection{Estimation method}

According to our proposed hypotheses, maternal mental health is modelled directly as a function of education together with other risk factors (test of hypothesis 1). Maternal education can have a direct impact on child nutritional status at age 1 and both direct and indirect impacts on cognitive development at age 5. Education can attenuate the relationship between maternal mental health and child development, and hence it is included as an important factor associated with maternal mental health and with both our defined outcomes for child development (test of hypothesis 2). Finally, we estimate the parameters of the path model separately for women of different educational levels. In doing so, we test whether maternal education changes the dynamics between maternal mental health and child development (test of hypothesis 3).

We construct a pathway model for the possible relations between maternal mental health, maternal education and child development, which takes into account the timing of these events (see Figure 1). We use structural equation models, maximum likelihood estimation, to analyse the relations between these key variables.

In order to develop a path model that better fits the data, preliminary independent linear regression models to predict maternal mental health and the two child development outcomes were conducted, and only covariates with a statistically significant relationship were included in the analysis. This was done to improve power analysis. In addition to socio-demographic factors associated with maternal depression (child health status, unwanted pregnancy, marital status, maternal health, number of siblings, bad event since pregnancy, place of residence), specific socio-demographic variables associated with child growth (wealth index, child age, place of residence, size at birth) and with child cognitive development (wealth index, child age, child pre-school attendance) have been included. Omission of these factors can strongly bias the estimation of parameters in the model. Covariance paths have been constrained to be zero when nonsignificant to improve power analysis. The final model includes an error term, $e_{i}$, for each of the key outcome variables (maternal mental health, child nutrition and child cognitive development).

We use a multi-group path analysis to investigate the model described in Figure 1 by mother's level of education. The fit of all models is determined by the Chi-square, Goodness of Fit Index (GFI), Comparative Fit Index (CFI), and Root Mean Square Error of Approximation (RMSEA). The chi-square test measures the comparability between models. The GFI gives the proportion of variance in the variance-covariance matrix explained by the model, and when its value exceeds 0.9 it ensures a good fit. The CFI compares the model with the independence model, where all paths among variables are considered to be zero, and it should also exceed 0.9. Finally the RMSEA estimated the lack of fit comparing our model with a saturated model (which includes all possible correlations within and between exogenous and endogenous variables) and its value should not exceed 0.05 .

For a sensitivity analysis, we estimated the same model on the subsample of women using Spanish as their first language, to check possible biases in the SRQ20 score due to women's ability to understand complex sentences. All the analyses were performed using SPSS AMOS.

\section{Results}

Figure 1 shows the Kernel density distributions for mother mental distress, child growth, and child cognitive development by mother's educational level. Mother level of education is a protective factor towards all the three indicators. Women with education below primary level achieve higher scores in the SRQ20 than women with levels of education above primary schooling (this result partially confirms hypothesis 1 ). The middle chart shows higher levels of HAZ among children whose mothers have more than primary education. Finally, we found that the distribution of PPVT scores, for children whose mothers have primary schooling or below, is skewed to the left in correspondence with lower PPVT scores. 
Figure 1. Kernell density function maternal mental health, HAZ, PPVT scores by mother's level of education

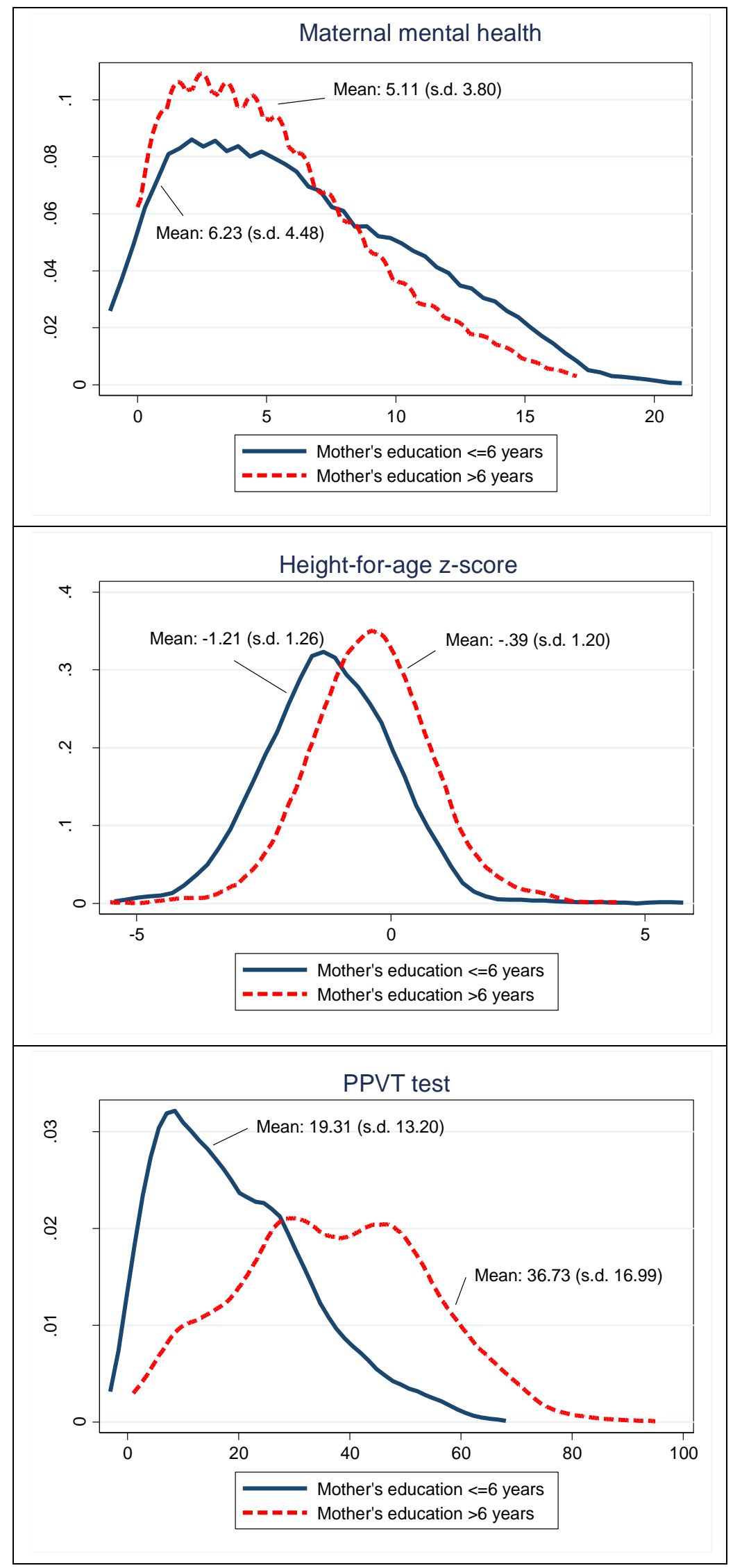


The path diagram where hypotheses 1 and 2 are tested is shown in Figure 2 (see Appendix Table A1, Model 1, for detailed results). Maternal education shows a direct and statistically significant association with mental health status (hypothesis 1). Maternal education is also associated with child nutritional status and child cognitive development, after controlling for the effect of other covariates.

Secondly, although there was a prior significant correlation between maternal mental health and child development, the final path model does not show a direct significant effect from maternal mental health (SRQ20) to children's cognitive development (PPVT) at age 5. Nonetheless, maternal education is found to be significantly associated with both of these factors, and its inclusion reduced the statistical significance level between maternal mental health and child cognitive development. This result confirms the role of maternal education in weakening the relationship between maternal mental health and child cognitive development (hypothesis 2 ).

Figure 2. Path diagram Model 1: standardized path coefficients

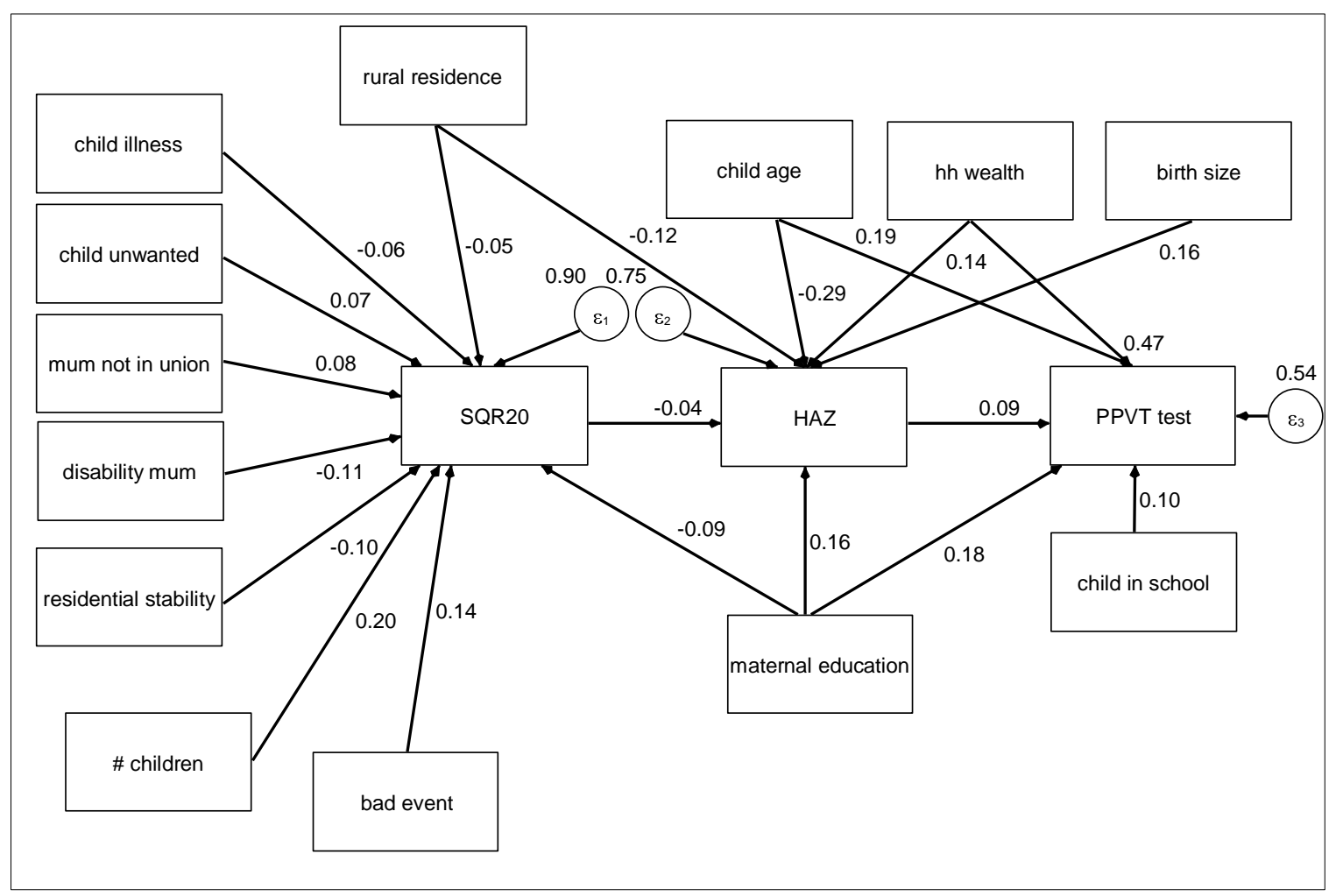

In order to test hypothesis 3, results from the path analysis were performed separately for women with 6 years or less schooling and for women with more than 6 years of schooling. Results are shown in Figure $3 a$ and $3 b$ (see Appendix Table A1, Model 2 and Model 3 for detailed results). We maintain identical models to let the non-significant paths emerge. Looking specifically at the pathway "maternal mental status-child nutritional status-child cognitive development", our results show that children of mothers with high SRQ20 scores tend to have lower nutritional status than children of mothers with low SRQ20 scores. However, this result is only supported for children of mothers with low education (st.est=-.067, p<.05) and not for children of mothers with high levels of education (st.est.=$.006, p>0.1)$. This result suggests that the nutritional status of the children tends to decrease by 0.067 standard units for each unit increase in their mothers' SRQ20 scores, only for children whose mothers have lower levels of education. Furthermore, the indirect effects of maternal mental health status on child cognitive development are statistically significant for the group of less educated mothers (st.est.=-.005, $p<.05)$, but not for children whose mothers have high levels of education (st.est.=-.003, $p>0.1$ ). 
Figure 3a. Path diagram Model 2: standardized path coefficients. Mother education $<=6$ years

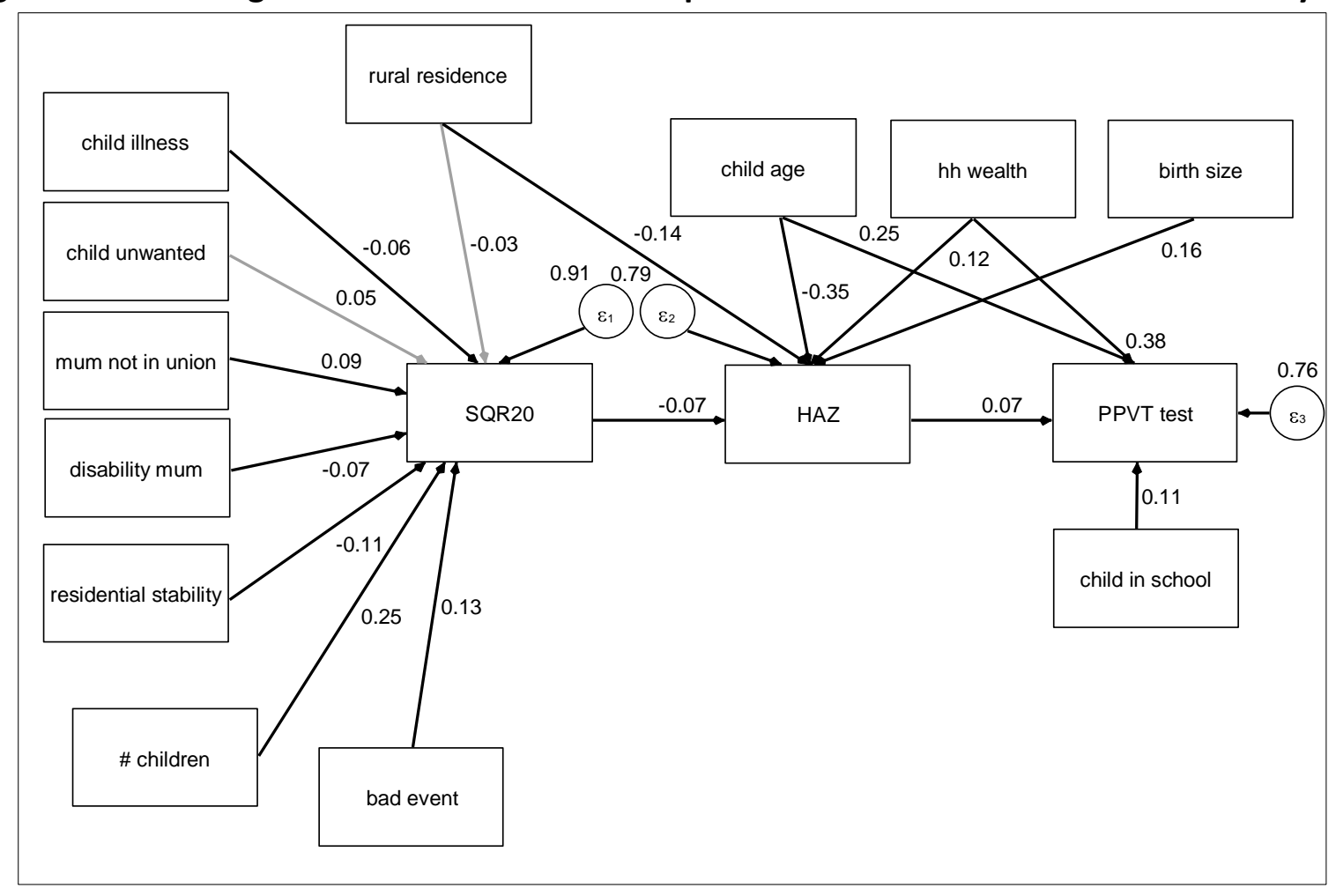

Notes. (1) Black arrows indicate statistical significance $<0.1$, grey arrows indicate statistical significance $>=0.1$

(2) Residual and covariance between covariates are included in the model but not shown in the diagram.

Figure 3b. Path diagram Model 3: standardized path coefficients. Mother education $>6$ years

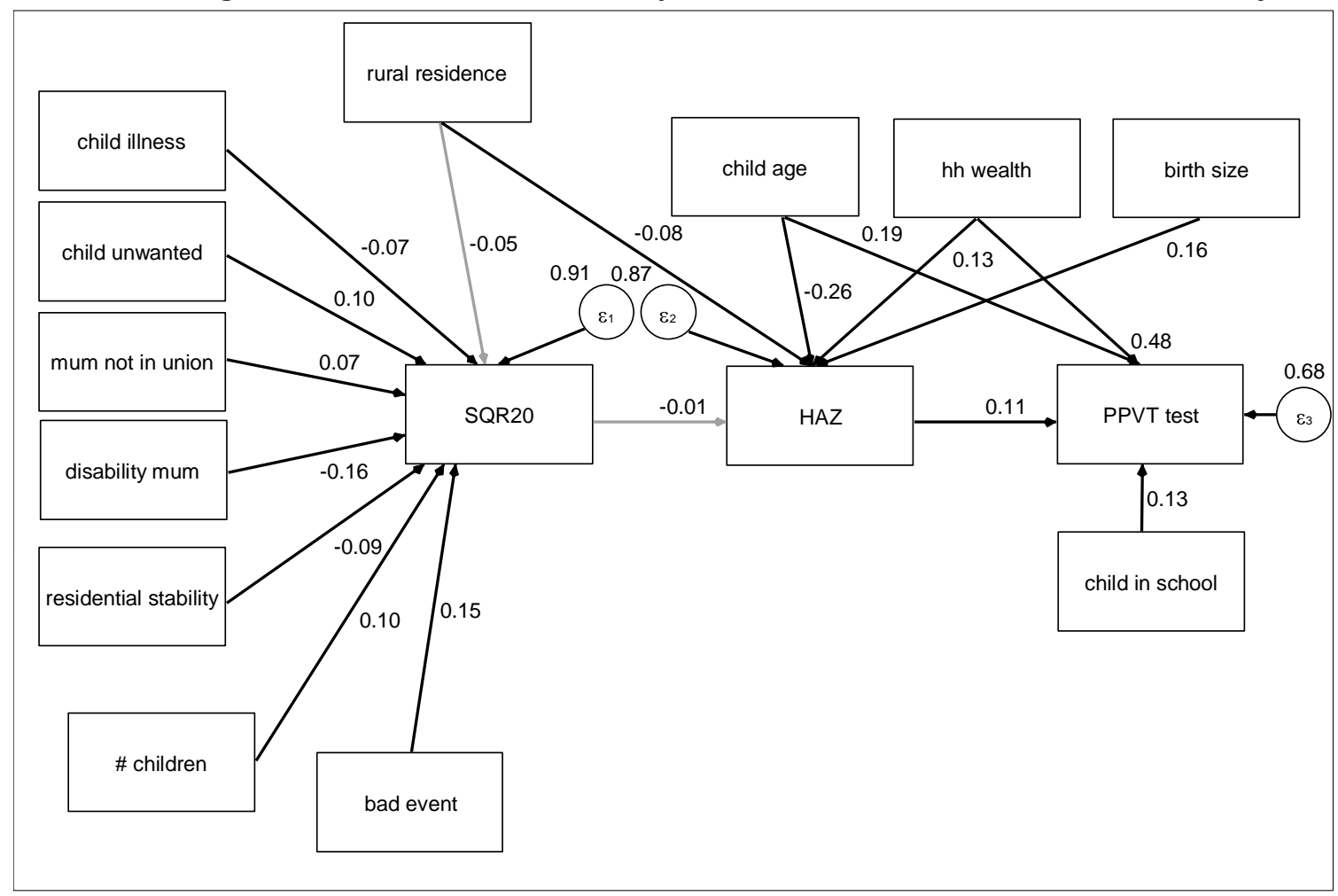

Notes. (1) Black arrows indicate statistical significance $<0.1$, grey arrows indicate statistical significance $>=0.1$

(2) Residual and covariance between covariates are included in the model but not shown in the diagram. 
Table 2 shows the measures of model fit for the two independent groups, showing good fit for both subsamples. In addition, a multi-group model has been estimated to test for measurement invariance across the two groups. Our unconstrained model has been compared to a constrained model, where all the parameters (paths) between covariates and outcomes have been constrained to be equal between groups. Looking at the chi-square difference between unconstrained and constrained models, we can conclude if the same model applies across groups or not. The measure of fit for this final procedure is shown in Table 3 . The unconstrained model has a slightly better fit than the constrained model, but more importantly, the chi-square difference test (chi-square=39.746, $\mathrm{df}=17$ ) between the unconstrained and constrained model is significant $(p<.001)$, suggesting that the hypothesis of invariance between the two groups is rejected. This therefore allows us to conclude that a difference exists in the path analysis between the two groups.

\section{Table 2. Model fit statistics}

\begin{tabular}{|l|l|l|l|l|l|}
\multicolumn{1}{c}{} & df & X2 & GFI & CFI & RMSEA \\
\hline Model 1 & 63 & 123.965 & .992 & .987 & .023 \\
Model 2 & 58 & 115.355 & .982 & .951 & .035 \\
Model 3 & 58 & 115.795 & .985 & .952 & .031 \\
\hline
\end{tabular}

Table 3. Model fit statistics for multi-group path analysis (mother's level of education)

\begin{tabular}{|l|l|l|l|l|l|}
\multicolumn{1}{c}{ df } & \multicolumn{1}{l}{ X2 } & \multicolumn{1}{l}{ GFI } & \multicolumn{1}{c|}{ CFI } & \multicolumn{1}{c|}{ RMSEA } \\
\hline Unconstrained & 116 & 231.154 & .984 & .023 & .951 \\
Constrained & 133 & 270.899 & .981 & .024 & .942 \\
\hline
\end{tabular}

There are other important results to highlight, which were obtained from the inclusion of covariates in the model (Table A1 in Appendix, Model 1). Focusing on maternal mental status, the strongest protective factor was residential stability (length of the time spent by the mother living in the same place). This dimension can be considered as a proxy of social capital, hypothesizing that the more the mother has been living in the same place, the more embedded she may be within the community, and the more protected by her own social network. The other contextual variable included in the model, i.e. rural place of residence at the time of the interview, has a direct positive effect on maternal mental status. As expected, child health affects mother mental wellbeing, with mothers of children who have never had a serious illness, being more likely to have a lower score in the SRQ20 test, hence better mental health. Among the strongest negative direct effects we detected was larger family size, having experienced a bad event, having some kind of disability (referred to the mother), being a single mother, and having had an unwanted pregnancy.

In addition to the association of maternal education with child nutritional status (which shows the strongest direct effect), age of the child, place of residence and maternal mental health status are associated with direct negative effects on child nutritional status. Living in a wealthier household and having been born into a normal to large size family is associated with higher HAZ.

Finally we find the expected association of child nutrition at age 1 on child cognitive development at age 5. We also find that children who attended preschool, those who were relatively older, whose mothers had higher levels of education, and those living in richer households, were more likely to achieve higher scores in the PPVT at age five than the rest of the children. The sensitivity analysis shows that results remained unchanged when only Spanishspeakers mothers are included in the analysis.

\section{Discussion}

This paper set out to investigate whether maternal education was directly associated with reduced likelihood of maternal mental health problems and improved developmental outcomes for their children, and whether maternal education could reduce the burden of maternal mental health problems on developmental outcomes for children. 
This last research question was hypothesised and investigated in terms of the potential moderating effect of maternal education.

Our results based on the Young Lives data for Peru confirmed previous empirical studies indicating the protective role of maternal education on maternal mental health (Chevalier \& Feinstein, 2006; Robertson et al., 2003; Ross \& Mirowsky, 1999) and child development (Black et al., 2007; Rahaman et al., 2002; Stewart, 2007). In particular we found that women with more education were less likely to selfreport mental health problems. We also found that women with more education were likely to have better nourished children with higher levels of cognitive development than the children of mothers with less education.

In terms of the effects of maternal education in reducing the burden of maternal mental health on child development, we found a strong protective effect. The inclusion of maternal education remains one of the key factors predicting improved developmental outcomes for children (Feinstein et al., 2008). This is not the case for maternal mental health. This result is consistent with previous studies which have found weakening relationships between maternal mental health and children's outcomes upon the inclusion of maternal education as a key protective factor (Augustine \& Crosnoe, 2010; Murray et al., 1996).

In terms of the moderating effect of education, our results show that the negative impact of maternal mental health problems on nutritional status and, indirectly on cognitive development, hold only for children whose mothers had low levels of education. Among children whose mothers had high levels of education, no significant direct or indirect effect of maternal mental health problems on child development were detected. These results are in line with Augustine and Crosnoe (2010) who found a negative relation between maternal mental illness and child cognitive development only for less educated women in the United States. It seems possible, therefore, that for women living in deprived areas of Peru, who managed to achieve levels of education beyond basic primary school, education plays a protective role not only for the general wellbeing of the mother, but also for the wellbeing of her child. However, less than half of women living in deprived areas of Peru failed to reach the basic level of primary education. These women lack the education to protect their children's physical and mental development against the effects of poor maternal mental health. This combination of disadvantage, as indicated by maternal mental health problems, economic deprivation and lack of maternal education, amongst other factors, is potentially responsible for the transmission of inequalities between generations (Exworthy, Blane \& Marmot, 2003; Palloni, Milesi, White, \& Turner, 2009).

With all its limitations in terms of availability of indicators and precision of measurements, this paper shows a clear role for maternal education, both as a protective factor and more importantly as a possible barrier to the transmission of inequalities between generations. If indeed women with low levels of education are those who are more likely to suffer from mental health problems, and more importantly, that their children are the ones more likely to lag behind nutritionally and academically, then the widening of inequalities between generations is likely to get even larger. In fact, these results are obtained for a relatively homogenous group in the Young Lives sample of Peru, so it is expected that for the whole population, inequalities in early life are likely to be even larger and the protective role of mother's education even more important. Therefore, this paper suggests that more analysis is needed in different communities so that particular interventions can be designed to help to tackle the transmission of these inequalities. We believe that monitoring of maternal health and child health, as well as provision of support for mothers with low levels of education, seem to be especially important if inequalities across future generations are to be reduced.

\section{Acknowledgements}

This research was funded by a grant from The BUPA Foundation (TBF-S09-034) entitled: "Access to education and child health." Research from this paper was presented at the Reproductive Morbidity and Poverty Workshop Announcement, 6th November 2010, London School of Economics, UK. Ethical approval was granted by the University of Sussex. The authors are grateful to the UK Data Archive and the Young Lives Team for their efforts in making the Young Lives Data available for research. We are especially thankful to Dr Rod Bond for his support and comments on the estimation of SEM models. 


\section{References}

Augustine, J.M., \& Crosnoe, R. (2010). Mothers' depression and educational attainment and their children's academic trajectories. Journal of Health and Social Behavior, 51, $274-290$. doi: $10.1177 / 0022146510377757$

Boyden, J. (2006). Young Lives Project: conceptual framework. Project document http://www.younglives.org.uk/publications/project-documents

Black, M., Baqui, A.H., Zaman K., McNary, S.W., Le, K., Arifeen, SE., Hamadani, J.D., Parveeb, M., Yunus, M., \& Black, R.E. (2007). Depressive symptoms among rural Bangladeshi mothers: Implications for infant development. Journal of Child Psychology and Psychiatry, 48, 764-772.

Card, D. (1999). The causal effect of education on earnings. In O. Ashenfelter \& D. Card (Eds.), Handbook of Labor Economics (pp. 1801-1859). Amsterdam: Elsevier-North Holland.

Carneiro, P., Meghir, C., \& Parey, M. (2013). Maternal education, home environments, and the development of children and adolescents. Journal of the European Economic Association, 11(s1), 123-160. doi: 10.1111/j.1542-4774.2012.01096.x

Chevalier, A., \& Feinstein, L. (2006). Sheepskin or Prozac: The Causal Effect of Education on Mental Health. IZA Discussion Paper No. 2231. Available at SSRN: http://ssrn.com/abstract=923530

Cogill, S., Caplan, H., Alexandra, H., Robson, K., \& Kumar, R. (1986). Impact of postnatal depression on cognitive development in young children. British Medical Journal, 292, 1165-1167.

CSDH. (2008). Closing the gap in a generation: health equity through action on the social determinants of health. World Health Organization, Geneva.

Duncan, G., \& Brooks-Gunn, J. (2000). Family poverty, welfare reform, and child development. Child Development, 71, 188-196. doi: 10.1111/1467-8624.00133

Edhborg, M., Lundh, W., Seimyr, L., \& Widstroem, A. (2001). The long-term impact of postnatal depressed mood on mother-child interaction: A preliminary study. Journal of Reproductive \& Infant Psychology, 19, 61-71. doi: 10.1080/02646830123255

Education Policy and Data Center, EPDC. (2009). Pupil performance and age: A study of promotion, repetition and drop out rates among pupils in four age groups in 35 developing countries. Working Paper EDPC-09-02. Washington DC: Education Policy and Data Center.

Exworthy, M., Blane, D., \& Marmot, M. (2003). Tackling health inequalities in the United Kingdom: the progress and pitfalls of policy. Health Services Research, 38, 1905-1922, Part II. doi: 10.1111/j.14756773.2003.00208.x

Feinstein, L., Duckworth, K. \& Sabates, R. (2008). Education and the Family: Passing Success Across Generations. In Peter Aggleton \& Sally Power (Eds.), Foundations and Futures of Education (pp. 1-222). Oxford: Routledge.

Field, T., Healy, B., Goldstein, S., Perry, S., Bendell, D., Schanberg, S., Zimmerman, E.A., \& Kuhn, C. (1988). Infants of depressed mothers show depressed behaviours even with non-depressed adults. Child Development, 59, 1569-1579.

Galler, J., Harrison, R., Ramsey, F., Forde, V., \& Butler, S.C. (2000). Maternal depressive symptoms affect infant cognitive development in Barbados. Journal of Child Psychology and Psychiatry, 41, 747-757.

Grace, S.L., Evindar, A., \& Stewart, D.E. (2003). The effect of postpartum depression on child cognitive development and behavior: a review and critical analysis of the literature. Archives of Women's Mental Health, 6, 263-274.

Harpham, T., Reichenheim, M., Oser, R., Thomas, E., Hamid, N., Jaswal, S., Ludermir, A., \& Aidoo, M. (2003). Measuring mental health in a cost-effective manner. Health Policy and Planning, 18, 344-349. doi: 10.1093/heapol/czg041

Harpham, T., Huttly, S., De Silva, M.J., \& Abramsky, T. (2005). Maternal mental health and child nutritional status in four developing countries. Journal of Epidemiology and Community Health, 59, 1060-1064. doi:10.1136/jech.2005.039180

Kerr, K. \& West, M. (2010). BERA insight: schools and social inequality. London: British Educational Research Association.

Kiernan, K., \& Huerta, C. (2008). Economic deprivation, maternal depression, parenting and children's cognitive and emotional development in early childhood. The British Journal of Sociology, 59, 783-806. doi: 10.1111/j.1468-4446.2008.00219.x

Knitzer, J., Theberge, S., \& Johnson, K. (2008). Reducing Maternal Depression and Its Impact on Young Children: Toward a Responsive Early Childhood Policy Framework. Issue Brief 2. New York: National Center for Children in Poverty.

Lyons-Ruth, K., Zoll, D., Connell, D. \& Grunebaum, H. U. (1986). The depressed mother and her one-year-old infant: Environment, interaction, attachment and infant development. In E. Z. Tronick \& T. Field (Eds.), Maternal Depression and Infant Disturbance. New Directions for Child Development, 34, (pp. 61-82). Jossey-Bass : San Francisco.

Malik, S., \& Courtney, K. (2011). Higher education and women's empowerment in Pakistan. Gender and Education, 23, 29-45. doi: 10.1080/09540251003674071 
Miech, R.A., \& Shanahan, M.J. (2000). Socioeconomic status and depression over the life course. Health and Social Behavior, 41, 162-176.

Mirowsky, J., \& Ross, C. (2002). Depression, parenthood, and age at first birth. Social Science \& Medicine, 54, 1281-1298. doi: /10.1016/S0277-9536(01)00096-X

Murray, L. (1992). The impact of postnatal depression on infant development. Journal of Child Psychology and Psychiatry, 33, 543-561. doi: 10.1111/j.1469-7610.1992.tb00890.x

Murray, L., Kempton, C., Woolgar, M., \& Hooper, R. (1993). Depressed mothers' speech to their infants and its relation to infant gender and cognitive development. Journal of Child Psychology and Psychiatry, 34, 1083-1101.

Murray, L., Hipwell, A., Hooper, R., Stein, A. \& Cooper, P. (1996). The cognitive development of 5-year-old children of postnatally depressed mothers. The Journal of Child Psychology and Psychiatry, 37, 927-935.

Murray, L., \& Cooper, P.J. (1997). Postpartum depression and child development (Editorial). Psychological Medicine, 27, 253-260.

Outes-Leon, I., \& Dercon, S. (2008). Survey attrition and attrition bias in Young Lives. Young Lives Technical Note, 5.

Palloni, A., Milesi, C., White, R.G., \& Turner, A. (2009). Early childhood health, reproduction of economic inequalities and the persistence of health and mortality differentials. Social Science and Medicine, 68, 1574-1582. doi: 10.1016/j.socscimed.2009.02.009

Patel, V., DeSouza, N., \& Rodrigues, M. (2003). Postnatal depression and infant growth and development in lowincome countries: A cohort study from Goa, India. Archives of Disease in Childhood, 88, 34-37. doi: 10.1136/adc.88.1.34

Patel, V., Rahman, A., Jacob, K.S., \& Hughes, M. (2004). Effect of maternal mental health on infant growth in low income countries: new evidence from South Asia. British Medical Journal, 328, 3, 820-823. doi: 10.1136/bmj.328.7443.820

Paxson, C., \& Schady, N. (2005). Child health and economic crisis in Peru. World Bank Economic Review, 19, 203223. doi: 10.1093/wber/lhi011

Petterson, S.M., \& Albers, A.B. (2001). Effects of Poverty and Maternal Depression on Early Child Development. Child Development, 72, 1794-1813.

Psacharopoulos, G., \& Patrinos, H. (2002). Returns to investment in education: a further update. World Bank Policy Research Working Paper, No. 2881. Washington DC: The World Bank.

Rahaman, A., Harrington, R., \& Bunn, J. (2002). Can maternal depression increase infant risk of illness and growth impairment in developing countries? Child: Care, Health \& Development, 28, 51-56. doi:10.1136/bmjopen-2011-000523

Rahaman, A., Iqbal, Z., Bunn, J., Lovel, H., \& Harrington, R. (2004). Impact of maternal depression on infant nutritional status and illness. Archives of General Psychiatry, 61, 946-952. doi:10.1001/archpsyc.61.9.946

Robertson, E., Celasun, N., \& Stewart, D.E. (2003). Risk factors for postpartum depression. In D.E. Stewart, E. Robertson, C.L. Dennis, S.L. Grace, S.L., \& T. Wallington (Eds.), Postpartum depression: Literature review of risk factors and interventions. Available at: www.who.int/mental health/.../lit review postpartum depression.pdf

Ross, C. \& Mirowsky, J. (1999). Refining the association between education and health: The effects of quantity, credential, and selectivity. Demography, 36, 445-60.

Sanchez, A. (2009). Early nutrition and later cognitive achievement in developing countries. Background paper for the Education for All global monitoring report 2010: Reaching the marginalized. Paris: UNESCO.

Stewart, R.C. (2007). Maternal depression and infant growth - a review of recent evidence. Maternal and Child Nutrition, 3, 94-107.

Teti, D.M., Gelfand, D.M., Messinger, D.S., \& Isabella, R. (1995). Maternal depression and the quality of early attachment: An examination of infants, preschoolers, and their mothers. Developmental Psychology, 31, 364-376.

Tuan, T., Harpham, T., \& Huong, N.T. (2004). Validity and reliability of the self-reporting questionnaire 20 items in Vietnam. Hong Kong Journal of Psychiatry, 14, 15-18.

Wang, L., Wu, T., Anderson, J.L., \& Florence, J.E. (2011). Prevalence and risk factors of maternal depression during the first three years of child rearing. Journal of Women's Health, 20,711-718. doi:10.1089/jwh.2010.2232

Wilson, I., Huttly, S.R.A., \& Fenn, B. (2006). A case study of sample design for longitudinal research: Young Lives. International Journal of Social Research Methodology, 9, 351-365.

Wisniewski, S.L.W. (2009). Child nutrition, health problems, and school achievement in Sri Lanka. World Development, 38, 315-332. doi:10.1016/j.worlddev.2009.09.009.

WHO (1994). A user's guide to the self reporting questionnaire (SRQ). Division of Mental Health, Geneva: WHO. www.whqlibdoc.who.int/hq/1994/WHO MNH PSF 94.8.pdf

WHO (2010a). Mental health and development: targeting people with mental health conditions as a vulnerable group. Geneva: WHO. http://www.who.int/mental health/policy/mhtargeting/en/

WHO (2010b). Gender and women's mental health. Gender disparities and mental health: The facts. Geneva: WHO. http://www.who.int/mental health/prevention/genderwomen/en/ 
Appendix Table A1. Estimations: standardized parameters (st.est.) with standard error (s.e.), and p-value

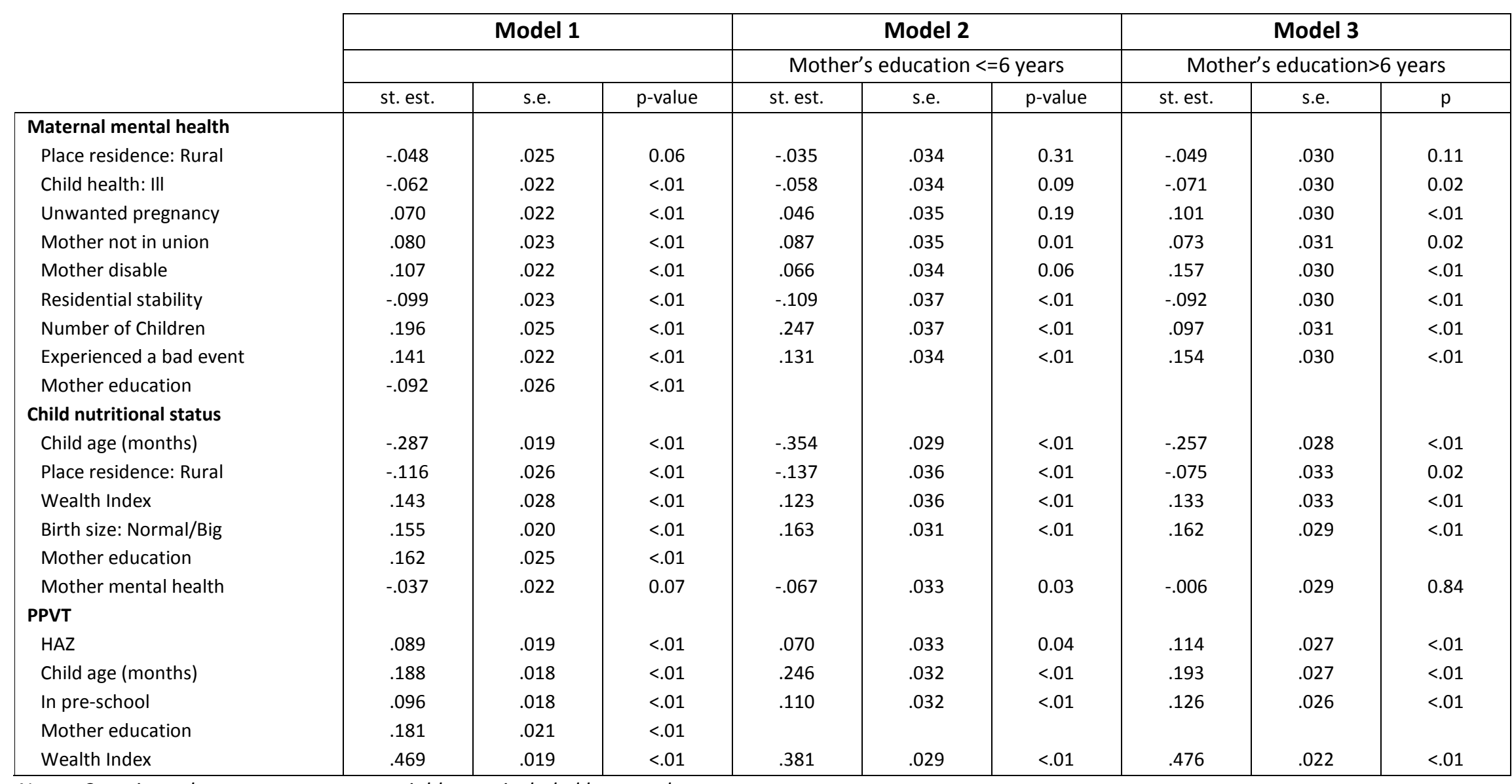

Notes. Covariance between exogenous variables are included but not shown

\section{Endnote}

'A threshold effect may occur higher than grade six, but this issue is only relevant if there are no differences with respect to the association between maternal education and maternal mental health, as well as between maternal education and children's nutritional and cognitive outcomes, which is not the case as it is demonstrated in the paper. 